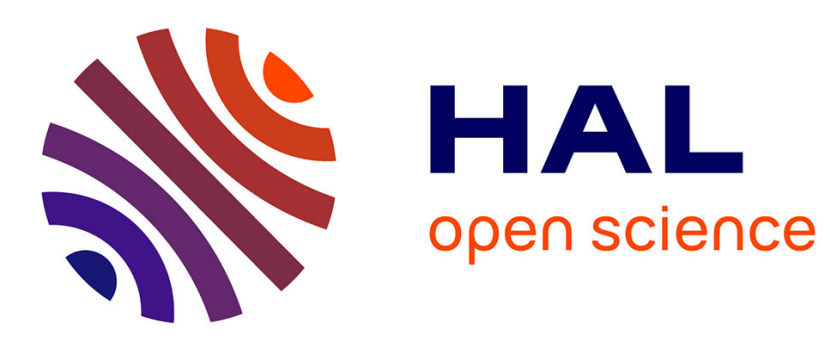

\title{
Modifications of RHT material model for improved numerical simulation of dynamic response of concrete Zhenguo Tu, Yong Lu
}

\section{To cite this version:}

Zhenguo Tu, Yong Lu. Modifications of RHT material model for improved numerical simulation of dynamic response of concrete. International Journal of Impact Engineering, 2010, 37 (10), pp.1072. 10.1016/j.ijimpeng.2010.04.004 . hal-00714935

\section{HAL Id: hal-00714935 \\ https://hal.science/hal-00714935}

Submitted on 6 Jul 2012

HAL is a multi-disciplinary open access archive for the deposit and dissemination of scientific research documents, whether they are published or not. The documents may come from teaching and research institutions in France or abroad, or from public or private research centers.
L'archive ouverte pluridisciplinaire HAL, est destinée au dépôt et à la diffusion de documents scientifiques de niveau recherche, publiés ou non, émanant des établissements d'enseignement et de recherche français ou étrangers, des laboratoires publics ou privés. 


\section{Accepted Manuscript}

Title: Modifications of RHT material model for improved numerical simulation of dynamic response of concrete

Authors: Zhenguo Tu, Yong Lu

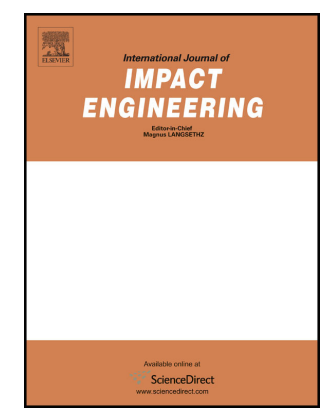

PII:

S0734-743X(10)00057-6

DOI:

10.1016/j.jijmpeng.2010.04.004

Reference: IE 1885

To appear in: International Journal of Impact Engineering

Received Date: 3 November 2008

Revised Date: 9 February 2010

Accepted Date: 8 April 2010

Please cite this article as: Tu Z, Lu Y. Modifications of RHT material model for improved numerical simulation of dynamic response of concrete, International Journal of Impact Engineering (2010), doi: 10.1016/j.ijimpeng.2010.04.004

This is a PDF file of an unedited manuscript that has been accepted for publication. As a service to our customers we are providing this early version of the manuscript. The manuscript will undergo copyediting, typesetting, and review of the resulting proof before it is published in its final form. Please note that during the production process errors may be discovered which could affect the content, and all legal disclaimers that apply to the journal pertain. 


\title{
Modifications of RHT material model for improved numerical simulation of dynamic response of concrete
}

\author{
Zhenguo Tu, Yong Lu * \\ Institute for Infrastructure and Environment, Joint Research Institute for Civil and \\ Environmental Engineering, School of Engineering, The University of Edinburgh \\ The King's Buildings, Edinburgh EH9 3JL, UK \\ * Corresponding author, Email: yong.lu@ed.ac.uk
}

\begin{abstract}
ABASTRACT
Sophisticated numerical models are increasingly used to analyze complex physical processes such as concrete structures subjected to high-impulsive loads. Among other influencing factors for a realistic and reliable analysis, it is essential that the material models are capable of describing the material behaviour at the pertinent scale level in a realistic manner. One of the widely used concrete material models in impact and penetration analysis, the RHT model, covers essentially all macro features of concrete-like materials under high strain rate loading. However, the model was found to exhibit undesirable performance under certain loading conditions and some of the modelling issues have been discussed within a recent review paper by the authors. The present paper provides a more in-depth evaluation of the RHT model and proposes modifications to the model formulation to enhance the performance of the model as implemented in the hydrocode AUTODYN. The modifications include Lode angle dependency of the residual strength surface, tensile softening law and the dynamic tensile strength function. The improvement of the performance of the modified RHT model is demonstrated using numerical sample tests, and further verified via simulations of two series of physical experiments of concrete penetration/perforation by steel projectiles. The results demonstrate an overall improvement of the simulation with the modified RHT model. In particular, the depth of penetration, projectile exit velocity and the crater size are predicted more favourably as compared to the test data. It is also shown that the modelling of the concrete tensile behaviour can affect sensibly the predicted perforation response (e.g. the projectile exit velocity), as is generally expected when the impact velocity exceeds the ballistic limit.
\end{abstract}

Keywords: constitutive model, concrete, dynamic load, penetration, numerical simulation, hydrocode 


\section{Introduction}

Concrete is a common material used in civil and defense constructions. Modeling of the concrete behaviour under static or quasi-static loading has been a subject of extensive studies for many decades. Modeling of the concrete behaviour under high rate loading is relatively new and it has become a topic of wide attention in more recent years. Apart from the needs to cope with the development of civil and defense industries for better protection of structures under extreme loading, a major reason is associated with the advancement of the computational power. Today, it has become possible to carry out large-scale numerical simulations that could reproduce many complex physical processes to great details. Numerical simulation using adequate computational models has become a powerful means in the design process as well as in the investigation into the physical mechanisms. In the high-impulsive load realm, a few examples of using numerical simulation to investigate the effects of the complex response of concrete under ballistic impact and explosion can be found in [1-4] with either user-developed codes or commercial hydrocodes such as AUTODYN [5] and LSDYNA [6].

Adequate material constitutive modeling and sound computational techniques are both essential to a reliable numerical simulation of complex responses. For brittle materials like concrete, the macroscopic inelastic response stems from material fracture, buckling and crushing of the cement paste and aggregate micro-structure [3]. These mechanisms become even more complex under high loading rate conditions. It is difficult to model the microscopic mechanical processes in the analysis of a real life problem. Instead, the modeling of the material constitutive behaviour for concrete-like materials is typically made at the macroscopic level that is consistent to the continuum description of the material using finite element methods. Nilsson [7] conducted some fundamental studies on the constitutive modelling of concrete subjected to high dynamic loads. A detailed description of the general modelling of concrete response using the theory of plasticity can be found in [8]. Recent advancements saw the development of several comprehensive concrete models that are aimed at high-impulsive load applications, with consideration of such effects as pressure hardening, strain hardening, material softening and rate-dependency. Models of this category include the RHT model $[1,9,10]$, the K\&C model [11,12] and JHC concrete model [13]. 
With the implementation in AUTODYN, the RHT model has been widely used in the modelling of concrete-like brittle materials for high-impulsive response analysis such as impact and penetration (e.g., [1-3,14]). Many of these applications made use of the model available in the software directly to simulate the responses concerned, and some conducted qualitative parametric studies with regard to the effect of critical model parameters on the prediction outcome. For example, Hansson and Skoglund [14] concluded from their simulation studies of projectile perforation problems that the parameters describing the damage accumulation and the residual strength surface in the material model are most sensitive with regard to the predicted projectile discharge velocity. Such parametric studies are important in that one could subsequently adjust the respective model parameter settings to achieve better predictions of the observed responses from relevant experimental studies. However, such a treatment could become problem-specific if the material model itself is not robust enough in representing the underlying physical mechanisms, for example the material softening at large deformations.

In a recent review study of concrete material models by the authors [15], several issues were identified with regard to the modeling capability of the RHT model in describing the concrete behaviour under certain stress conditions, and recommendations have been given as to how the model parameter settings may be adjusted to indirectly rectify the modeling issues within the existing standard RHT formulation. In the present study, we conduct a more comprehensive evaluation of the RHT model for concrete material and propose a set of changes to the model formulation in order to enhance the robustness of the model.

The model is first evaluated with regard to its ability of representing the stress-strain relationships of concrete subjected to various loading conditions, namely uniaxial tension, biaxial compression and triaxial compression. The evaluation is performed by single finite element numerical tests. The results will highlight the following: a) under a triaxial extension condition (corresponding to the tensile meridian), the model produces a stress-strain behavior that differs from what might generally be anticipated under such stress conditions, b) the default parameter configurations of the tensile-to-compressive meridian ratio requires modification to produce results more consistent with experimental observations, c) the ratedependency of concrete in tension needs to be updated to keep in line with generally accepted macroscopic dynamic enhancement functions. Furthermore, when the crack softening model in AUTODYN is employed to augment the RHT model concerning tension softening, the 
softening law should be carefully formulated to ensure an anticipated softening process while maintaining specified fracture energy.

The proposed modifications are presented along with brief descriptions of the background theory and experimental observations. These modifications are implemented with user coded subroutines via the respective interface modules provided by AUTODYN. The modified behaviour of the material model is demonstrated with numerical tests. The improvement of the modified material model is further verified via numerical simulations of concrete penetration by steel projectile, and comparisons are made among the predictions using the original RHT model, the modified RHT model proposed in this paper, and experimentalempirical results with regard to such characteristic responses as depth of penetration, projectile exit velocity, as well as size of the crater.

\section{Modifications to the standard RHT model}

The original RHT model is well documented in previous publications [1,5,9] and a concise overview is also provided in [15]. In this section, we will focus on the analysis of a few issues and present the detailed modifications to the original RHT model. The improved model performance due to the modifications is demonstrated by single finite element numerical tests.

\subsection{Modified residual strength surface}

As implemented in AUTODYN, the residual strength surface in the standard RHT model exhibits a circular deviatoric cross section plane in the principal stress space. This simplified treatment creates some difficulties in replicating the material behaviour under certain stress conditions, in that the model tends to exhibit a hardening response after the peak failure strength is reached instead of softening, as would normally be expected.

Let us first take a look of the relevant behaviour of the RHT model. For this purpose singleelement numerical tests are performed. The single-element specimen is given a cubic shape, and it is loaded by monotonically increasing the compressive displacements (hence the compressive strain) along two principal directions, while a constant stress is imposed in the $3^{\text {rd }}$ principal direction. This loading path corresponds to a Lode angle of zero degree, i.e. on the tensile meridian. Fig. 1 shows typical compressive stress-strain curves as obtained from the above numerical tests using the original RHT model. As can be seen, all the results exhibit 
a hardening phenomenon, even in the biaxial compression state when the stress in the $3^{\text {rd }}$ direction is made equal to zero.

Such a persistent hardening phenomenon is deemed to be unrealistic for concrete-like materials. Although systematic experimental data about the stress-strain response of concrete under general triaxial extension are not commonly available, the special case of biaxial compression has been studied extensively in the past and softening is typically observed (e.g., [16]). Besides, numerous triaxial compression tests exist and the general observation also suggests a post-peak softening trend (e.g. [17]).

In order to understand further the reason behind the above-mentioned problem in the model, the path of the yield stress developed in the numerical specimen during the loading process is tracked, as shown in Fig. 2. It can be immediately observed that, as a result of the lode-angle independent residual strength adopted in the model, the (tensile) meridian of the residual surface actually goes beyond that of the failure surface. Consequently, the stress continues to increase (hardens) when it moves from the failure surface towards the residual surface.

To rectify the hardening problem, one possible way, without changing the shape of the residual surface, is to reduce the residual strength constant B (see Eq. (1) below) in the model altogether. However, this would affect the overall model behaviour. A more viable approach, as is proposed here, is to modify the residual strength surface to make it Lode angle dependent in a similar way as for the maximum strength surface, i.e.,

$$
Y_{\text {residual }}= \begin{cases}B \times\left(p^{*}\right)^{M} \times r_{3}(\theta) & p \geq 0 \\ 0 & p<0\end{cases}
$$

where $r_{3}(\theta)$ is a scalar function of Lode angle $\theta$ and the function $\psi$ [8],

$$
r_{3}(\theta)=\frac{r}{r_{c}}=\frac{2\left(1-\psi^{2}\right) \cos \theta+(2 \psi-1) \sqrt{4\left(1-\psi^{2}\right) \cos ^{2} \theta+5 \psi^{2}-4 \psi}}{4\left(1-\psi^{2}\right) \cos ^{2} \theta+(1-2 \psi)^{2}}
$$

where $\psi=\frac{r_{t}}{r_{c}}$ denotes the tensile-to-compressive meridian ratio (refer to Fig. 3) and is a function of the pressure.

The tensile meridian of the above modified residual surface is also shown in Fig. 2 for a comparison. It can be seen that the modified tensile meridian maintains under the failure 
surface. This ensures a softening behaviour, which is deemed to represent the general concrete behaviour, at least within a reasonably high pressure range. It should be noted that in the modified residual strength surface the compressive meridian remains unchanged from the original model.

The above modification to the residual surface of the RHT model is then implemented in AUTODYN by adding user subroutines into the external strength interface module. Eq. (1) is used to compute the residual strength value at the current pressure. This value, together with the calculated current failure strength, is then used to solve for the current yield stress.

With the modified residual strength surface, the same numerical tests as for Fig. 1 are repeated, and the results are shown in Fig. 4. It can be seen that with the modification the model reproduces a softening behaviour after reaching the maximum strength. Furthermore, as the compressive stress in the $3^{\text {rd }}$ (axial) direction increases, the material becomes stronger and more ductile. This is consistent with general experimental observations (e.g., [16-17]).

It is worth mentioning that, an alternative approach to modelling the post-failure response, without actually using a residual strength function, is to penalize with damage the normalized hydrostatic tension (e.g., [18]). In this way one saves two parameters (B and M in Eq. (1)), and avoids the uncertainties associated with the deviatoric shape in the residual function. However, introducing an independent residual failure surface, as is adopted in RHT and some other models (e.g., [11-12]), is deemed to be a generalized consideration. By bringing in two additional free parameters $\mathrm{B}$ and $\mathrm{M}$, it gives more flexibility in accommodating test observations under different loading conditions.

\subsection{Modified tensile-to-compressive meridian ratio vs pressure relationship}

In the RHT model, the tensile-to-compressive meridian ratio $\psi$ is defined to depend linearly on the pressure $p$ as:

$\psi(p)=C_{0}+C_{1} \times p / f_{c}$

where $C_{0}$ and $C_{1}$ are two constant coefficients and $f_{c}$ is the unconfined concrete compressive strength. In AUTODYN, the suggested values of $C_{0}$ and $C_{1}$ are respectively 0.6805 and 0.0105 , thus, 
$\psi(p)=0.6805+0.0105 \times p / f_{c}$

However, it is found that with Eq. (4) the model cannot represent satisfactorily the expected strength of concrete in or close to a biaxial compression. It is generally expected that the strength of concrete under biaxial compression loading is around 1.15 times the unconfined uniaxial compressive strength [11]. For example, for $35-\mathrm{MPa}$ concrete the biaxial compressive strength should be around 41.0 MPa. But with Eq. (4) the model would give a considerably higher biaxial compressive strength (see later in Fig. 6).

Based on a collection of test data, Malvar et al. [11] recommended a piece-wise linear definition of $\psi$ in the $\mathrm{K} \& \mathrm{C}$ Concrete Model, as follows:

$$
\psi(p)=\left\{\begin{array}{cc}
1 / 2 & p \leq 0 \\
1 / 2+3 f_{t} / 2 f_{c} & p=f_{c} / 3 \\
\alpha f_{c} /\left[a_{0}+\left(2 \alpha f_{c} / 3\right) /\left(a_{1}+2 a_{2} \alpha f_{c} / 3\right)\right] & p=2 \alpha f_{c} / 3 \\
0.753 & p=3 f_{c} \\
1.0 & p \geq 8.453 f_{c}
\end{array}\right.
$$

The detailed descriptions and the determination of $\alpha, a_{0}, a_{1}$ and $a_{2}$ in Eq. (5) can be found in Malvar et al. [11,12].

In this study, we propose to retain the simple form of Eq. (3), but using modified values for $C_{0}$ and $C_{1}$ so as to better match the trend as represented by Eq. (5). For this purpose, three sets of data are obtained from Eq. (5) for concrete grade $35 \mathrm{MPa}, 70 \mathrm{MPa}$ and $150 \mathrm{MPa}$, respectively. Actually, in Eq. (5) only one control point of $\psi(p)$, at $p=f_{c} / 3$, is sensitive to the concrete strength grade. At this point $\psi(p)$ is defined as a function of the concrete tensileto-compressive strength ratio, and it is generally known that this ratio tends to be smaller for higher strength concrete.

Through a linear regression analysis with the aforementioned three sets of data points, the best-fit $C_{0}$ and $C_{1}$ are found to be 0.60 and 0.05 , respectively. The relationship using the above $C_{0}$ and $C_{1}$ values is shown in Fig. 5. As can be observed, the corresponding $\psi(p)$ appears to match the piecewise expression given by Eq. (5) in almost the entire pressure range, except for pressure well below $f_{c} / 3$. 
By using the modified $\psi(p)$ as above, together with the change of the residual strength surface as described in Section 2.1, the concrete biaxial compression response can be reasonably reproduced by the model. As shown in Fig. 6, for the 35-MPa concrete, the biaxial compressive strength produced by the modified model becomes very close to the expected value of $41 \mathrm{MPa}$, while the result produced using the default $\psi(p)$ in the standard RHT is about $30 \%$ larger.

2.3 Modifications to the modeling of tensile behaviour of concrete

Plain concrete is weak and brittle under tension. Crack softening is a characteristic feature of concrete and requires specific modeling considerations. Besides, the tensile strength of concrete is known to be strain rate sensitive under dynamic loading; the rate dependent law has a significant effect on the modeling result. The standard RHT model has a limited capability in representing the tension-cracking behaviour, whereas its rate-dependent law is not up-to-date.

It is possible to implement through user subroutines a user-defined dynamic increase factor (DIF) to rectify the dynamic tensile strength and a crack softening law to improve the tensile behaviour of the model (e.g., Leppenen [19]). In the present study, in conjunction with other modifications we also propose to implement a modified DIF. Furthermore, for the tension softening we propose to use a bi-linear softening function that would enable the retention of a specific fracture energy during the dynamic response. For the sake of completeness, some background information about the rate effect on concrete and the crack softening model will be briefly described along with the proposed modifications.

\subsubsection{Concrete dynamic tensile strength increase factor}

It has been established through dynamic experiments that concrete behaviour is rate-sensitive. The general experimental observations tend to indicate that the bulk strength of concrete increases with the increase of strain rate, especially in the high strain rate regime (e.g. [2021]). At this juncture, it may be worth noting that the interpretation of the experimental data from the high strain rate tests is a subject of constant scrutiny; depending on the scale of observation there may be different explanations as to what is the real cause of the experimentally observed rate sensitivity of the concrete strength (e.g., [22-24]). A detailed discussion on the underlying mechanisms is beyond the scope of the present paper. The 
modification discussed here is mainly concerned with a generalized macroscopic modeling framework for which RHT model is best suited, and from a macroscopic point of view it is rational to adopt the experimentally observed rate effect on the dynamic strength of concrete specimens.

Within the framework of a macroscopic model the rate-dependent strength of the concrete material is usually modeled by expanding the failure surface by a certain Dynamic Increase Factor (DIF). In the standard RHT model as implemented in AUTODYN, the DIF for both tension and compression is expressed as a linear function of the strain rate in the logarithmic scale, as:

$\operatorname{DIF}(\dot{\varepsilon})= \begin{cases}\left(\frac{\dot{\varepsilon}}{\dot{\varepsilon}_{0}}\right)^{d} & \text { for tension } \\ \left(\frac{\dot{\varepsilon}}{\dot{\varepsilon}_{0}}\right)^{a} & \text { for compression }\end{cases}$

where $d$ and $a$ are constants. The quasi-static strain rate $\dot{\varepsilon}_{0}$ is taken as $3.0 \times 10^{-6} s^{-1}$ for tension and $3.0 \times 0^{-5} s^{-1}$ for compression.

The above expressions of DIF are simple, but it is not consistent with experimental observations which tend to support a bi-linear (log-scale, refer to Fig. 7) DIF expression. This discrepancy is particularly significant for the dynamic tensile strength as the transition strain limit in the tensile DIF is low (around $1 \mathrm{~s}^{-1}$ ) and is easily reached. This necessitates a modification of the tensile DIF. For the compressive DIF, the linear expression in Eq. (6) may be regarded as acceptable for a large strain rate range of interest, and therefore is not modified in the present study.

There are several bi-linear expressions of DIF, typical of which include the CEB-FIB formulas for both tension and compression [25]. For the dynamic tensile strength of concrete, Malvar and Ross [21] studied a large set of experimental data and proposed a modified version of the CEB-FIB model, as: 


$$
\operatorname{DIF}(\dot{\varepsilon})= \begin{cases}\left(\frac{\dot{\varepsilon}}{\dot{\varepsilon}_{s}}\right)^{\delta} & \text { For } \dot{\varepsilon} \leq 1 s^{-1} \\ \beta\left(\frac{\dot{\varepsilon}}{\dot{\varepsilon}_{s}}\right)^{1 / 3} & \text { For } \dot{\varepsilon}>1 s^{-1}\end{cases}
$$

where $\dot{\varepsilon}_{s}$ is the quasi-static strain rate, $\dot{\varepsilon}_{s}=1 \times 10^{-6} s^{-1}, \delta$ is a constant relating to the grade of concrete represented by the compressive strength, $\delta=1 /\left(1+8 f_{c s} / f_{c o}\right)$, with $f_{c o}=10 \mathrm{MPa}$ (1450 psi). The coefficient $\beta$ is a function of $\delta, \log \beta=6 \delta-2$.

To highlight the difference between the "linear" and "bi-linear" expressions, a comparison of the two tensile DIF functions is shown in log-scale in Fig. 7. As noted by Leppanen [19], while Eq. (7) reasonably depicts the experimental DIF in tension, the linear expression in Eq. (6) cannot achieve a satisfactory match. Therefore, in the present study, we also choose to implement the bi-linear DIF function for an improved representation of the dynamic tension behaviour of the RHT model. It is understood that the effect of modifying the DIF function on the general simulation results can be case dependent. From the simulation of steel projectile penetration in concrete, as will be discussed in more detail later, the severity of material scabbing and spallation can be quite sensitive to the DIF model used.

It is noted that in order for the above modified DIF to take effect in the RHT model the implementation should be done through the crack softening failure option in the model. A more detailed discussion about the cracking softening model follows.

2.3.2 Implementation of a bi-linear softening model with consideration of rate independent fracture energy

In the standard RHT model, the tensile behaviour of the material is described by a plasticitydamage tensile failure model (hereafter referred to as plasticity-damage model), in which the material damage is calculated based on the accumulation of the equivalent plastic strain relative to a pressure-dependent failure strain variable.

Two issues are identified concerning the modeling of the concrete tensile behaviour with the above plasticity-damage model. Firstly, a minimum strain criterion $\left(\varepsilon_{\min }\right)$ is used to control the tensile failure and this criterion generally dictates the material response in the low pressure 
regime, e.g., in uniaxial and biaxial tension cases. As a result, the specific fracture strain energy will tend to increase almost proportionately with the increase of the tensile strength in the strain rate regime. This could result in an overestimation of the energy consumed in the concrete fracture process, and subsequently an underestimation of the damage such as the penetration depth, as will be shown later in the penetration example.

The second issue with such a plasticity-damage model is that it cannot handle properly scenarios where the loading condition is close to the isotropic triaxial tension. This is because in such loading conditions the material incurs only volumetric deformation; however, the RHT model does not consider the volumetric damage, consequently the predicted response would exhibit no softening. Although a pure triaxial tension or a stress path close to it is only a special case and is unlikely to make any significant impact in the real problem analysis, for the sake of rigor and coherency it would be desirable that the material behavior under all plausible stress conditions be well represented in the model.

The crack softening model in AUTODYN could be employed to overcome the abovementioned difficulties in describing the tension behaviour of concrete. This general crack softening model is based on the consideration that in the low pressure region the tension failure of concrete is likely to be governed by the principal tensile stress, instead of the deviatoric straining. Accordingly, a Rankine failure surface is introduced to define the maximum principal strength criteria for the initiation of the tensile failure [26]. When such a crack softening model is used in conjunction with the RHT model, the Rankine failure surface is superimposed onto the RHT strength functions. In this way, the crack softening model will come into effect when the response of an element falls into the lower pressure regime bounded by the interface between the Rankine and RHT strength surfaces. In such a situation, when the Rankine failure criteria are violated, the stresses are returned to the failure surface following an associative backward Euler method [26].

At this juncture, it may be worth noting that the post-peak tensile behaviour (softening) is not strictly a material property; and in addition to the tensile strength and fracture energy the shape of the softening behaviour has an influence on the load-carrying capacity of concrete. The existing crack softening model adopts a linear softening law, which assumes a constant strength degradation rate with respect to the cracking strain in the entire fracture process. However, general experimental observations tend to support that the tension softening branch 
of concrete is close to an exponential function [27-29]; hence, a bi-linear function for softening appears to be a better approximation. Considering the generality, in the present study we choose to follow a bi-linear softening law proposed by Gylltoft [28], as schematically illustrated in Fig. 8. In this model, the tensile strength reduces rapidly at the early stage of failure up to one-sixth of the cracking strain, followed by a slower decreasing rate until the attainment of the total fracture at the maximum cracking strain $\varepsilon_{\text {frac }}$ (at which point a real crack emerges).

The crack softening model implemented in AUTUDYN follows a smeared crack approach, such that the discrete crack width is smeared out over a certain distance, which is normally equal to the characteristic length of the element. Thus, for a given fracture energy, $G_{f}$, the following specific strain energy in the entire cracking process should hold:

$\int_{\varepsilon_{e l}}^{\varepsilon_{\text {frac }}} \sigma d \varepsilon=G_{f} / h_{c}$

where $G_{f}$ denotes the fracture energy, $\varepsilon_{e l}$ is the strain at peak tensile stress, i.e. the starting strain of softening, $h_{c}$ is the characteristic length of the element. In a two-dimensional analysis, $h_{c}$ is approximately the square root of the area of the element [30], while in a threedimensional analysis, $h_{c}$ may be approximated by the cube root of the volume of the element. It is worth pointing out that satisfying Eq. (8) also ensures a relative mesh-objectivity in maintaining a target amount of the fracture energy in a finite element model.

In the existing linear softening model in AUTODYN, Eq. (8) is used to first establish the crack limit strain $\varepsilon_{\text {frac }}$ for a given fracture energy $G_{f}$ under a quasi-static condition. This crack limit strain is then kept unchanged during the response. Under dynamic loading, this scheme effectively results in an almost proportionate increase of the fracture energy as the dynamic tensile strength increases with the strain rate. In the bilinear softening model implemented by Leppanen [19], which also follows the Gylltoft bi-linear function in Fig. 8, the two softening slope values were evaluated from the linear softening slope calculated by AUTODYN such that the same fracture energy as in the linear softening model is retained. This implies that the fracture energy achieved in such a bi-linear scheme will also increase with the strain rate in a similar way as the linear softening model. 
However, so far the experimental data regarding the strain rate effect on the fracture energy of concrete has been very scattered [27, 31-32]. Although some individual studies tend to suggest certain increase in the fracture energy at high rates, for example Weerheijm and Doormaal [27], and Schuler et al. [33], in general it is still difficult to draw any clear correlation. Under such a circumstance, in the present study we choose to adopt a rate independent fracture energy approach in our implementation of the bi-linear softening model, as described in detail in what follows. The general effect will be discussed in association with the penetration simulation examples later.

According to the basic bi-linear relationship shown in Fig. 8, it can be easily figured out that $\mathrm{k}_{1}=4 f_{t s} / \varepsilon_{\text {frac }}$ and $\mathrm{k}_{2}=0.4 f_{t s} / \varepsilon_{\text {frac }}=0.1 \mathrm{k}_{1}$, where $f_{\text {ts }}$ denotes the static tensile strength. By satisfying the fracture energy equation (8), we have

$$
\int_{0}^{\varepsilon_{\text {frac }}} \sigma d \varepsilon=\left(f_{t s} / 3+f_{t s}\right) \times \varepsilon_{\text {frac }} / 6 / 2+f_{t s} / 3 \times 5 \times \varepsilon_{\text {frac }} / 6 / 2=f_{t s} \times \varepsilon_{\text {frac }} / 4=G_{f} / h_{c}
$$

Thus:

$$
\varepsilon_{\text {frac }}=\frac{4 G_{f}}{f_{t s} h_{c}}
$$

and hence following Fig. 8,

$$
\mathrm{k}_{1}=-d \sigma / d \varepsilon=4 f_{t s} / \varepsilon_{\text {frac }}=f_{t s}^{2} h_{c} / G_{f}, \quad \mathrm{k}_{2}=-d \sigma / d \varepsilon=0.1 k_{1}=f_{t s}^{2} h_{c} / 10 G_{f}
$$

In the damage-based algorithm adopted in AUTODYN, the softening slope parameter is specified and evaluated in terms of the damage index. To distinguish from the slope defined in Eq. (11) the softening slope in the damage-strain scale is denoted as $\mathrm{k}_{\mathrm{D}}$ herein. Also, denoting the damage induced by the tensile cracking as $D_{t}$, we have

$$
\mathrm{k}_{\mathrm{D}}=d D_{t} / d \varepsilon
$$

Similar to the general damage definition, $D_{t}$ varies from 0 to 1 . In the calculation, $D_{t}$ is evaluated as the total stress reduction with respect to the concrete tensile strength, i.e.,

$$
D_{t}=\left(f_{t s}-\sigma\right) / f_{t s}
$$

Subsequently, the two slope parameters become:

$$
\mathrm{k}_{\mathrm{D} 1}=d D_{t} / d \varepsilon=f_{t s} h_{c} / G_{f}, \quad \mathrm{k}_{\mathrm{D} 2}=1 / 10 \mathrm{k}_{1}=f_{t s} h_{c} / 10 G_{f}
$$


The actual energy dissipation over the softening process in a dynamic loading condition may be controlled by replacing the static tensile strength $f_{t s}$ in Eq. (14) with a factored dynamic strength parameter. In the present study, we propose to keep a rate independent fracture energy, and this can be achieved by replacing $f_{t s}$ directly with the variable dynamic tensile strength $f_{t d}$, i.e.,

$$
\mathrm{k}_{\mathrm{D} 1}=f_{t d} h_{c} / G_{f}, \quad \mathrm{k}_{\mathrm{D} 2}=f_{t d} h_{c} / 10 G_{f}, \quad \text { where } f_{t d}=\operatorname{DIF}(\dot{\varepsilon}) \times f_{t s}
$$

It should be noted that the damage incurred in the tensile cracking regime $\left(D_{T}\right)$ mentioned above will understandably cumulate into the general damage $(D)$ in the overall evolution of the material damage. Therefore, if the subsequent response of the element develops into the normal plasticity regime governed by the RHT model, the material behaviour will carry an influence from $D_{T}$.

To demonstrate the adequacy of using the present bi-linear tension softening model as compared to the linear softening model, numerical tests are performed to simulate the uniaxial tension of class $35-\mathrm{MPa}$ concrete with a quasi-static tensile strength of $3.5 \mathrm{MPa}$. The characteristic length is assumed to be $10 \mathrm{~mm}$, with the specific fracture energy $G_{f}=100 \mathrm{~J} / \mathrm{m}^{2}$. The input tensile strength for fracture $\left(f_{t d}^{\text {input }}\right)$ is $3.5 \mathrm{MPa}$. Two strain rates equal to $20 \mathrm{~s}^{-1}$ and $100 \mathrm{~s}^{-1}$, respectively, are considered.

Fig. 9 shows the tensile stress-strain curves generated by the linear crack softening model for the two different strain rates. It can be seen that the fracture energy measured by the area under the stress-strain curve increases proportionately with the increase of the dynamic tensile strength, and this could result in an overestimation of the energy dissipation. On the other hand, as shown in Fig. 10, the implementation of the present bi-linear softening model enables the realization of a pre-defined fracture energy for different strain rates. In fact, by adjusting the slopes of the bi-linear damage curves $\left(\mathrm{k}_{\mathrm{D} 1}\right.$ and $\left.\mathrm{k}_{\mathrm{D} 2}\right)$, as mentioned earlier, it would be possible to reflect a certain degree of the rate effect on the fracture energy if future experimental evidence indicates that this is more appropriate.

Generally speaking, with the adoption of the crack softening model, the triaxial tension behavior of concrete can be well represented, instead of the unrealistic perfectly-plastic 
response resulted from the use of the plasticity-damage model. Fig. 11 shows the improved isotropic tri-axial tension response generated by the present bi-linear crack softening model.

\section{Numerical examples and comparison with experimental results}

The improvements of the RHT model with the proposed modifications have been clearly demonstrated at the constitutive modeling level by the numerical tests on single-element specimens under various stress conditions. In this section, the improved performance of the modified RHT model is further verified through the numerical simulation of a complex problem involving impact and penetration. The key response parameters predicted by the numerical calculations are compared with physical experimental results.

The experiments of impacting plain concrete targets by steel projectile reported by Hansson [34] and Unosson and Nilsson [3] are simulated. Two characteristic response parameters, namely the depth of penetration and the projectile exit velocity, are used for a verification purpose. In the experiment by Hansson [34], the crater size is also available and this is compared with the simulation result as well.

\subsection{General modeling considerations}

For the numerical simulation of solids involving large deformation, such as the present problem with penetration of hard projectile in concrete, several computational methods exist for the modeling of the deformation and the movement of the solid materials for example Lagrangian method, Eulerian method, the Arbitrary Lagrangian Eulerian (ALE) method, and various meshless methods such as the Smooth Particle Hydrodynamics (SPH) method.

In AUTODYN, the RHT model may be used in a standard Lagrangian finite element environment, and it may also be used with the SPH method. In the present simulation of the penetration/perforation tests, the standard Lagrangian finite element method is used for modeling both the projectile and the concrete target. To tackle the numerical difficulty that could arise when elements incur severe distortion, the so-called element erosion technique is employed.

It should be mentioned for the penetration/perforation type of analysis, where the element erosion is primarily engaged for numerical considerations, the erosion strain limit is usually 
assigned to be large enough so as to minimize any adverse effect from removing elements. However, there is still some trade-off between retaining the residual effect of a distorted element and the numerical errors due to excessive distortion, in addition to the modeling error. Therefore to some extent the choice of a proper erosion limit is still a case dependent, somewhat empirical matter. For penetration and perforation simulations, our experience by performing a sensitivity study with erosion strains ranging from $50 \%$ to $350 \%$ tends to suggest that $150 \%$ or around that level is a good choice. This also echoes the recommendations made by some other researchers (e.g., [2]). Hence, in the present simulations a strain limit of $150 \%$ is adopted for activating the element erosion.

\subsection{Simulation of the experiment by Hansson [34]}

In the experiment conducted by Hansson [34], a projectile was shot with zero attack angle into a large cylinder target made of plain concrete. The steel projectile has an ogive nose of caliber-radius-head (CRH) 3.0 , length $225 \mathrm{~mm}$, diameter $75 \mathrm{~mm}$, and density $7830 \mathrm{~kg} / \mathrm{m}^{3}$. The total mass of the projectile is $6.28 \mathrm{~kg}$. The steel material has the following properties: bulk modulus $159 \mathrm{GPa}$, shear modulus $81.8 \mathrm{GPa}$, and yield stress $792 \mathrm{MPa}$. The impact velocity was measured to be $485 \mathrm{~m} / \mathrm{s}$.

The cylindrical concrete target has a length of $2.0 \mathrm{~m}$ and diameter of $1.6 \mathrm{~m}$. The concrete compressive strength obtained from tests of $150-\mathrm{mm}$ cubic specimens is about $40 \mathrm{MPa}$. The tensile strength is determined to be $2.64 \mathrm{MPa}$ and the fracture energy is $100 \mathrm{~J} / \mathrm{m}^{2}$.

The post-test measurement from two shots gave a penetration depth of $655-660 \mathrm{~mm}$. The dimension of the crater produced was also measured and the diameter was about $800 \mathrm{~mm}$.

Four comparative simulations are performed to demonstrate the improved behaviour of the modified RHT model as compared to the results using the standard RHT model. The computational model settings are kept the same among the four simulations, except the RHT material model. A uniform mesh size of $8 \mathrm{~mm}$ is found to be suitable and is used in the simulations.

The four different RHT model settings used in the four simulations, respectively, are designated as follows:

- "RHT1": standard RHT with a plasticity-damage description for tension 
- "CSA-NDIF": RHT with linear "crack-softening" model, and without DIF

- "CSA-UDIF": RHT with linear "crack-softening" model, and with modified DIF

- "RHT-M": modified RHT model, as detailed in Section 2.

Fig. 12 shows the attenuation of the projectile velocity as it penetrates into the concrete target in the four different simulations. The final damage patterns of the concrete targets are compared in Fig. 13.

When the standard RHT with a tensile plasticity-damage model is used (simulation "RHT1"), the predicted depth of penetration is about $430 \mathrm{~mm}$ as compared to the measured $655 \mathrm{~mm}$ in the physical experiment, i.e., with an underestimation by about $50 \%$. As will be shown later, a similar problem also occurs when this model setting is applied in the simulation of the perforation/penetration tests. A significant overestimation of the fracture energy dissipation under the plasticity-damage model, as discussed in section 2.2, is deemed to be responsible for the marked underestimation of the penetration depth. It is also interesting to note from Fig. 13 that a visible rebound occurs in the RHT1 simulation. This phenomenon also tends to indicate that the material appears is overly strong in the fractured zone in front of the penetration tunnel.

In the simulation "CSA-NDIF" where the linear crack softening model is used, without considering any tensile DIF, it can be expected that the material is considerably weak in tension. As a result, the simulated penetration depth is found to be $801 \mathrm{~mm}$, which is about $23 \%$ higher than the measured result. The concrete damage pattern shown in Fig. 13(b) exhibits much more extensive damage as compared with Fig. 13(a). Besides, from Fig. 13 (b) it can also be observed that noticeable damage in the form of scabbing also occurs at the rear side of the target, and this again can be attributed to the weaker tensile strength of the material as represented by this particular model setting. It is noted that no rebound occurs in this simulation.

In the third simulation "CSA-UDIF", which follows the same model setting as "CSA-NDIF" except the use of the modified DIF for tension, the material behaves much stronger in resisting the penetration. In conjunction with the overly estimated fracture energy due to the linear crack softening model, the predicted depth of penetration sharply reduces to $622 \mathrm{~mm}$, which is lower than the experimental result, while the diameter of the crater becomes significantly under-predicted, with a value of $520 \mathrm{~mm}$ as compared to the measured $800 \mathrm{~mm}$. 
In the final simulation "RHT-M", the modified RHT model is used with a proper consideration of the tension DIF, the fracture energy and the residual strength surface. The overall improvement in the simulation results is evident. The depth of penetration is predicted to be $685 \mathrm{~mm}$, which is very close to the measurement of $655 \mathrm{~mm}$, while the simulated crater diameter is $720 \mathrm{~mm}$ which also agrees well with the experimental result of $800 \mathrm{~mm}$.

It is worth keeping in mind that the experimental data from penetration/perforation tests often involve a large scatter. Therefore, caution should be exercised when interpreting the comparison with limited experimental data. The comparison shown above is focused on a relative observation with regard to the effect of the proposed modifications in a real problem simulation.

\subsection{Simulation of the experiments by Unosson and Nilsson [3]}

Unosson and Nilsson [3] conducted two series of experiments, namely a series of perforation tests, in which the projectile breached through the target and exited with a residual velocity, and a series of penetration tests, where the projectile came to rest inside the target. In both cases, the projectile was shot in the normal direction to a plain concrete target of cylindrical geometry. The steel projectile has an ogive nose with caliber-radius-head also equal to 3.0. The total length of the projectile is $225 \mathrm{~mm}$ and the diameter is $75 \mathrm{~mm}$. The total mass of the projectile is $6.3 \mathrm{~kg}$. The steel material of the projectile has a yield stress of $2.0 \mathrm{GPa}$.

In the perforation experiments, the length (thickness) of the target is $0.4 \mathrm{~m}$ and the diameter is $1.4 \mathrm{~m}$. The target used in the penetration experiments has a length of $0.8 \mathrm{~m}$ and a diameter of $1.4 \mathrm{~m}$. The targets are all made of high strength concrete, with an unconfined compressive strength of $153 \mathrm{MPa}$. The tensile strength of the concrete is determined to be $8.2 \mathrm{MPa}$ and the fracture energy is $162 \mathrm{~J} / \mathrm{m}^{2}$. The density of the concrete is $2770 \mathrm{~kg} / \mathrm{m}^{3}$.

For each series of the tests, three shots were performed in order to observe the consistency of the test results. The target specimens were cast from the same batch of concrete. Table 1 gives the projectile impact velocities and the measured results. For the perforation tests, the mean exit velocity is about $291 \mathrm{~m} / \mathrm{s}$, while for the penetration tests, the mean penetration depth is approximately $0.5 \mathrm{~m}$. The variation of the individual test results from the mean is within $5 \%$ for the perforation tests and $10 \%$ for the penetration tests. 
For the simulations of both series of tests, a uniform mesh size of $5 \mathrm{~mm}$ is used. This is consistent with the mesh size of $8 \mathrm{~mm}$ used in the simulation of Hansson's test, considering the difference in the overall dimensions of the concrete targets. Similar to the simulations for Hansson's experiment, four different simulations are carried out for each type of tests, using the four different concrete material model settings as described in Section 3.2.

Fig.14 shows a comparison of the attenuation of the projectile velocity with the penetration distance in the perforation simulations using models "RHT1" and "RHT-M", respectively. Note that the target thickness is $0.4 \mathrm{~m}$, so the terminal velocity at penetration distance of 0.4 $\mathrm{m}$ represents the exit velocity. The damage patterns just before the perforation are shown in Fig. 15.

From Fig. 14, it can be observed that the projectile exit velocity from the simulation using the "RHT1" setting with a plasticity-damage model for tension is about $200 \mathrm{~m} / \mathrm{s}$, which is much lower than the average test result of $291 \mathrm{~m} / \mathrm{s}$. With the modified RHT model, the simulation results are markedly improved, and the simulated exit velocity is about $335 \mathrm{~m} / \mathrm{s}$.

The simulation results for the penetration tests are depicted in Fig. 16 and 17. Similar to the observations made from the simulation of Hansson's experiment described in Section 3.2 and the perforation tests described above, the "RHT1" model again exhibits an overly strong resistance and high energy absorption capacity of the concrete, leading to a considerable underestimation of the penetration depth equal to $260 \mathrm{~mm}$ as compared to the measured value of $500 \mathrm{~mm}$. Also, after reaching the maximum penetration depth, the projectile is bounced back at a certain speed (herein equal to about $50 \mathrm{~m} / \mathrm{s}$ ), as clearly seen from Fig. 17(a). This phenomenon was contrary to the observation from the actual tests, where the projectile was found to be embedded in the targets.

The simulation results using the modified RHT model show clear improvements. The simulated depth of penetration is about $460 \mathrm{~mm}$, which is very close to the measured $500 \mathrm{~mm}$. It is worth mentioning that Unosson and Nilsson [3] actually conducted numerical simulations for this penetration test also. Their simulations were performed using LS-DYNA [6], and the $\mathrm{K} \& \mathrm{C}$ concrete model $[11,12]$ was employed for modeling the concrete material. Their results showed that the projectile could not come to rest in the target; instead, perforation occurred with the projectile exit velocity being as high as $200 \mathrm{~m} / \mathrm{s}$. 


\section{Concluding remarks}

The RHT material model has a comprehensive framework that encompasses many important features of concrete-like brittle materials under high impulsive loading. However, numerical tests indicate that this material model, as implemented in AUTODYN, falls short in representing the concrete behaviour under certain loading conditions, particularly concerning the tension response and softening behaviour. To a certain extent, these problems may be corrected by appropriately determining the influencing model parameters. The present paper proposes to rectify the issues by incorporating modifications to the model formulation. The proposed modifications include the adoption of a Lode angle dependent residual strength surface, a modified definition of the pressure-dependency of the tensile-to-compressive meridian ratio, and the use of a common (bi-linear) dynamic increase factor function for the tensile strength. Furthermore, a modified bi-linear crack softening law is proposed to control the dynamic tension softening process.

The above modifications are implemented to the RHT model in AUTODYN through user codes. With the modifications, the RHT model is found to behave more realistically in modeling the concrete behaviour in tension as well as in compression. The unwanted hardening phenomenon of the model under specific stress conditions such as a biaxial compression is eliminated due to the incorporation of the Lode angle dependent residual strength. The proposed bi-linear crack softening function is capable of satisfying a given fracture energy for varying strain rates, and thus avoids the overestimation of the energy consumption in the fracture process.

Numerical simulation of penetration of concrete targets by steel projectile is conducted to further evaluate the performance of the modified RHT model in real applications. The results from simulations of a series of physical penetration/perforation experiments demonstrate appreciable improvements in the damage patterns, as well as in the predicted parameters including the depth of penetration, projectile exit velocity and the size of the crater

\section{References}

[1] Riedel W, Thoma K, Hiermaier S. Penetration of reinforced concrete by BETA-B-500-numerical analysis using a new macroscopic concrete model for hydrocodes. Proceedings of $9^{\text {th }}$ 
International Symposium on Interaction of the Effect of Munitions with Structures. 1999. p.31522.

[2] Leppanen, J. Dynamic behaviour of concrete structures subjected to blast and fragment impacts. Thesis for the degree of licentiate of engineering. Chalmers University of Technology, Goteborg, Sweden; 2002.

[3] Unosson M, Nilsson L. Projectile penetration and perforation of high strength concrete: experimental results and macroscopic modelling. Int J Impact Eng 2006;32:1068-85.

[4] Rabczuk T, Eibl J. Modelling dynamic failure of concrete with meshfree methods. Int J Impact Eng 2006; 32:1878-97.

[5] AUTODYN Theory Manual (Revision 4.3). Century Dynamics, Inc.: 2003.

[6] LS-DYNA Keyword User's Manual, version 970. Livermore Software Technology Corporation; 2003.

[7] Nilsson L. Impact loading on concrete structures: a constitutive modelling, finite element analysis, and experimental study of nonlinear wave propagation. Doctoral thesis, Chalmers University of Technology, Goteborg, Sweden; 1979.

[8] Chen W.F. Plasticity in Reinforced Concrete. New York: McGraw Hill; 1982.

[9] Riedel W, Kawai N and Kondo K. Numerical Assessment for Impact Strength Measurements in Concrete Materials, International Journal of Impact Engineering 36 (2009), pp. 283-293 DOI information: 10.1016/j.ijimpeng.2007.12.012.

[10] Riedel W. Beton unter dynamischen Lasten: Meso- und makromechanische Modelle und ihre Parameter, ed.: Fraunhofer EMI/IRB, Freiburg 2004, ISBN 3-8167-6340-5.

[11] Malvar LJ, Crawford JE, Wesevich JW, Simons D. A plasticity concrete material model for DYNA3D. Int J Impact Eng. 1997; 19(9-10): 847-73.

[12] Malvar L J, Crawford JE, Morrill KB. K\&C concrete material model Release III - Automated generation of material model input. K\&C technical report TR-99-24-B1; August 18, 2000 (limited distribution).

[13] Holmquist TJ, Johnson GR, Cook WH. A computational constitutive model for concrete subjected to large strains, high strain rates, and high pressures. $14^{\text {th }}$ International Symposium on Ballistics. Quebec, Canada; 1993. p.591-600.

[14] Hansson H, Skoglund P. Simulation of concrete penetration in 2D and 3D with the RHT material model. Technical Report FOI-R-0720-SE, Swedish Defence Research Agency, Tumba, Sweden; 2002.

[15] Tu ZG, Lu Y. Evaluation of typical concrete material models used in hydrocodes for high dynamic response simulations. Int J Impact Eng 2009; 36: 132-146.

[16] Chen W-F. Plasticity in Reinforced Concrete. (reprint, 1982), J. Ross Publishing Classics, 2007.

[17] Lu X, Hsu C-T T. Stress-strain relations of high-strength concrete under triaxial compression. Journal of Materials in Civil Engineering, ASCE, 2007; 19(3): 261-268. 
[18] Polanco-Loria M, Hopperstad OS, Børvik T and Berstad T. Numerical predictions of ballistic limits for concrete slabs using a modified version of the HJC concrete model. Int J Impact Eng 2008; 35: 290-303.

[19] Leppanen J. Concrete subjected to projectile and fragment impacts: modelling of crack softening and strain rate dependency in tension. Int J Impact Eng 2006;32:1828-41.

[20] Bischoff PH, Perry SH. Compression behavior of concrete at high strain-rates. Mater. Struct. 1991; 24: 425-450.

[21] Malvar LJ, and Ross CA. Review of strain rate effects for concrete in tension. ACI Mat J 1998; 95(6): 735-39.

[22] Li QM, Meng H. About the Dynamic strength enhancement of concrete like materials in a split Hopkinson pressure bar test, Int J Solids and Structures 2003; 40: 343-360.

[23] Cotsovos DM, and Pavlovic MN. Numerical investigation of concrete subjected to compressive impact loading. Part 1: A fundamental explanation for the apparent strength gain at high loading rates. Computers \& Structures 2008; 86:145-163.

[24] Lu Y, Song ZH, Tu ZG. Numerical simulation study of the strain rate effect on concrete in compression considering material heterogeneity. Proc. DYMAT 2009, Brussels, Belgium, 7-11 September 2009.

[25] Comité Euro-International du Beton, CEB-FIB Model Code 1990. Trowbridge, Wiltshire, UK: Redwood Books; 1993.

[26] Clegg RA, Hayhurst CJ and Robertson I. Development and application of Rankine plasticity model for improved prediction of tensile cracking in ceramic and concrete materials under impact, 14th DYMAT Technical Meeting, Sevilla, Spain, November, 14-15, 2002.

[27] Weerheijm J, Van Doormaal JCAM. Tensile failure of concrete at high loading rate: New test data on strength and fracture energy from instrumented spalling tests. Int J Impact Eng 2007;34(3):609-26.

[28] Gylltoft K. Fracture mechanics models for fatigue in concrete structures. Doctoral thesis, Division of Structural Engineering, Lulea University of Technology, Lulea, Sweden; 1983.

[29] Hillerborg A. The theoretical basis of a method to determine the fracture energy $\mathrm{G}_{\mathrm{f}}$ of concrete. Mat Struct 1985;18(106): 291-6.

[30] Johansson M. Structural behavior in concrete frame corners of civil defense shelters, non-linear finite element analyses and experiments. Doctoral Thesis, Department of Structural Engineering, Chalmers University of Technology, Goteborg, Sweden; 2000.

[31] Brara A, Klepaczko JR. Fracture energy of concrete at high loading rates in tension. Int J Impact Eng 2007; 34(3): 424-35.

[32] Zielinski AJ. Fracture of concrete and mortar under uniaxial impact tensile loading. PhD thesis. Delft University of Technology: Delft University Press; 1987. 
[33] Schuler H., Mayrhofer C. and Thoma K. Spall experiments for the measurement of the tensile strength and fracture energy of concrete at high strain rates. Int J Impact Eng 2006: 32; 16351650.

[34] Hansson H. Numerical simulation of concrete penetration. Technical Report FOA 98-00816311-SE, Defense Research Establishment, Tumba, Sweden; 1998. 
Table-1 Measured results of the perforation and penetration tests

\begin{tabular}{c|c|c|c|c}
\hline \multirow{2}{*}{ Test category } & Shot no. & $\begin{array}{c}\text { Projectile } \\
\text { impact velocity } \\
(\mathrm{m} / \mathrm{s})\end{array}$ & $\begin{array}{c}\text { Projectile exit } \\
\text { velocity }(\mathrm{m} / \mathrm{s})\end{array}$ & $\begin{array}{c}\text { Depth of } \\
\text { penetration }(\mathrm{m})\end{array}$ \\
\hline \multirow{3}{*}{ Perforation test } & 1 & 616 & 276 & N.A. \\
\cline { 2 - 5 } & 2 & 616 & 303 & N.A. \\
\cline { 2 - 5 } & 3 & 618 & 293 & N.A. \\
\cline { 2 - 5 } Penetration test & 1 & 617 & N.A. & 0.45 \\
\cline { 2 - 5 } & 2 & 612 & N.A. & 0.54 \\
\hline
\end{tabular}




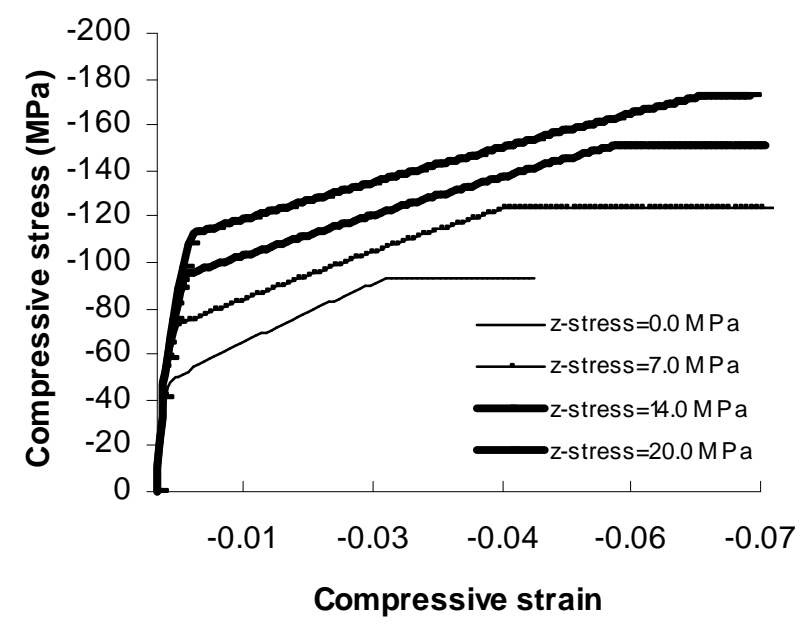

Fig. 1. Stress-strain curves under different loading conditions corresponding to the tensile meridian.

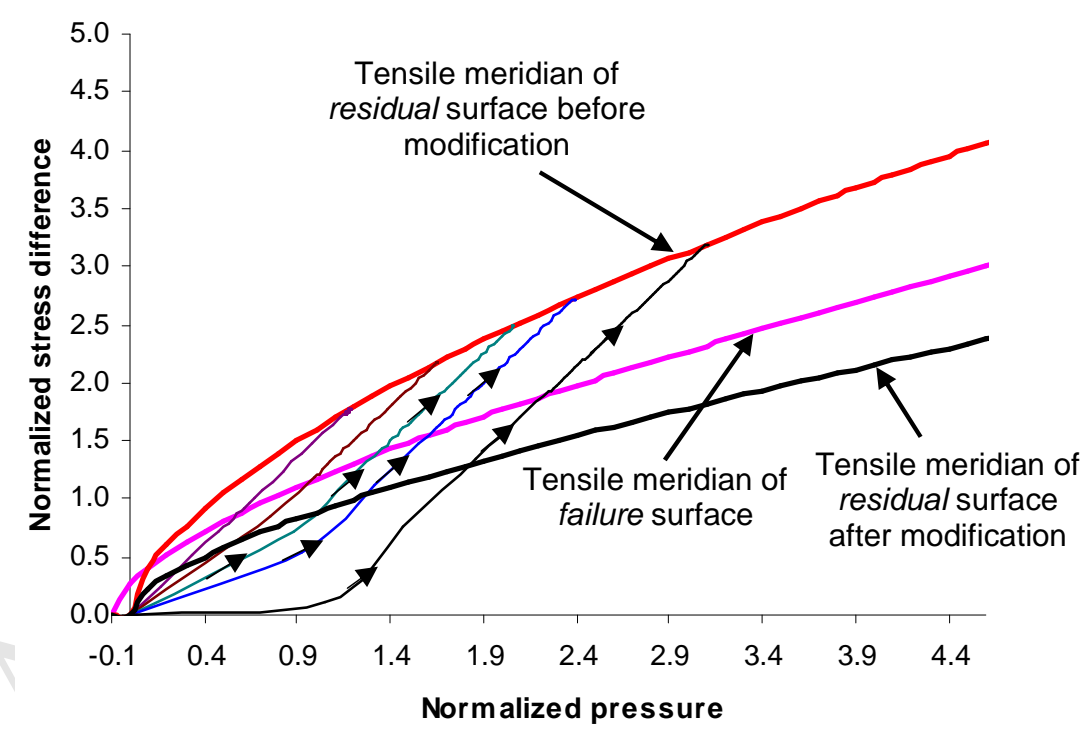

Fig. 2. Illustration of stress development paths corresponding to the tensile meridian (zero lode angle). 


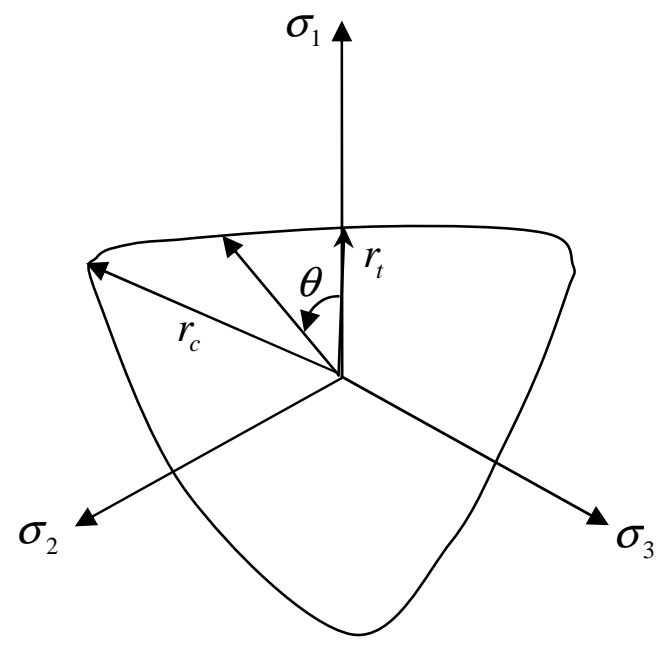

Fig. 3. Typical deviatoric cross section plane of material strength surfaces.

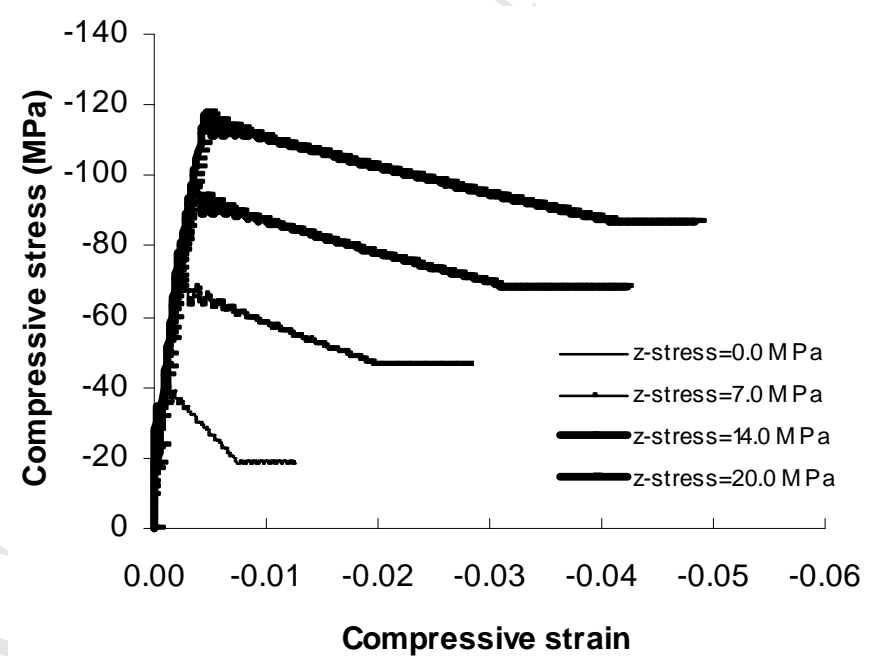

Fig. 4. concrete responses corresponding to the tensile meridian generated by the RHT model with modified residual strength surface. 


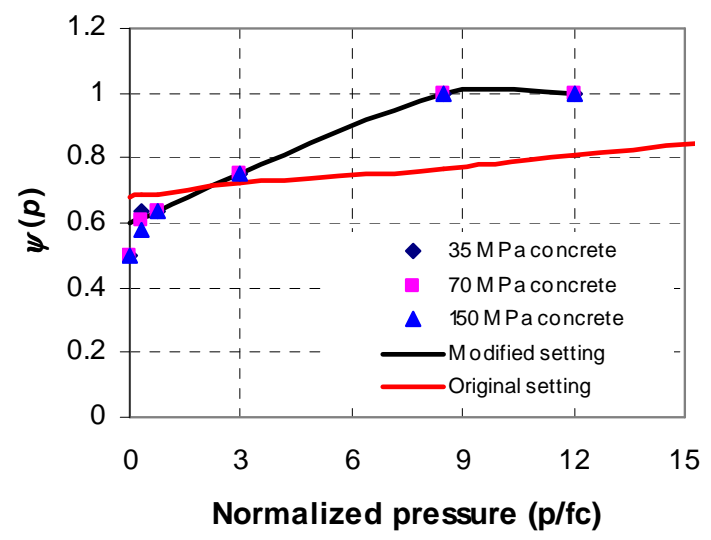

Fig. 5. Comparison of $\psi(p)$ (dots = recommended values by Malvar et al. [12]).

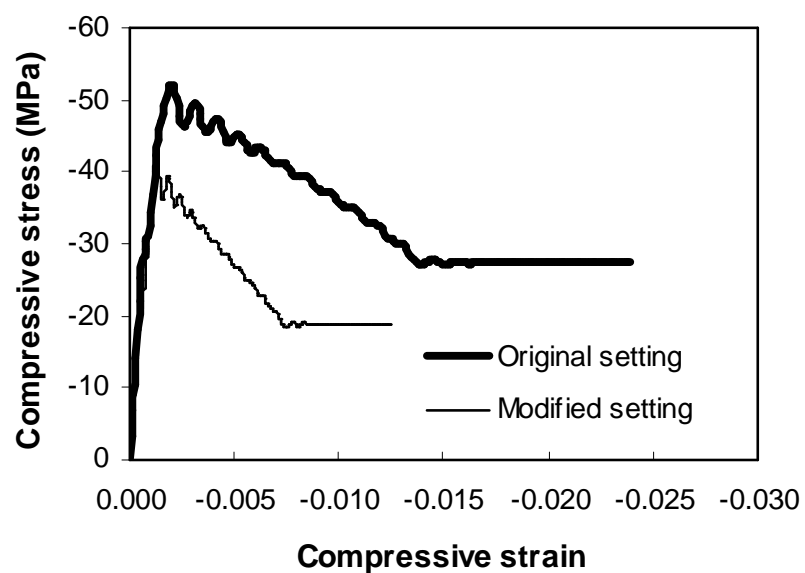

Fig. 6. Improved biaxial compression stress-strain relationship by the proposed $\psi(p)$. 


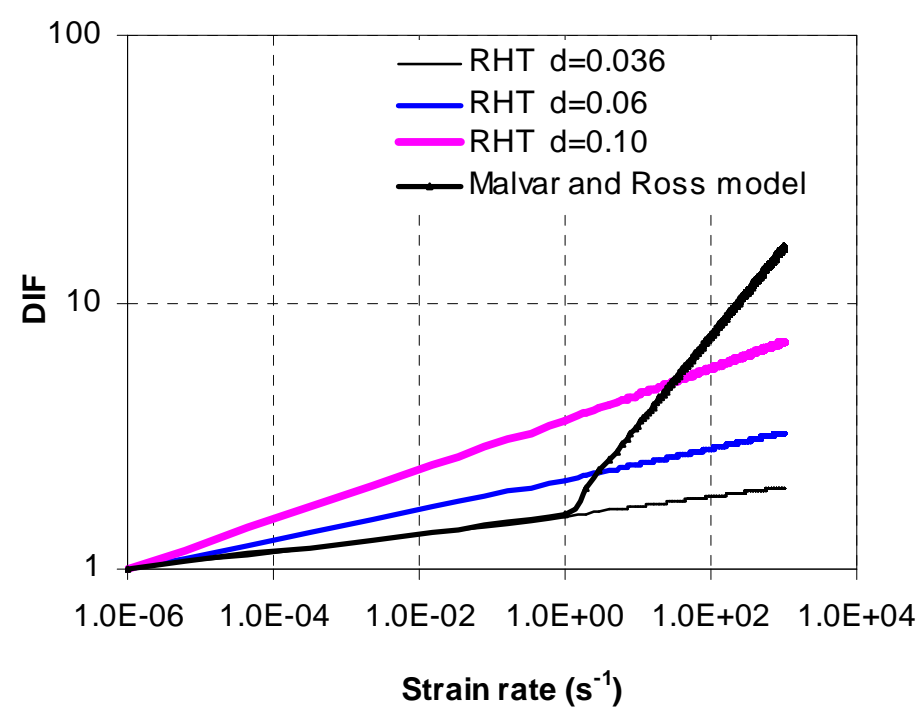

Fig. 7. Comparison of concrete tension DIF in RHT model with the model adopted in the modification.



Fig. 8. Illustration of uniaxial tension bi-linear crack opening model [28]. 


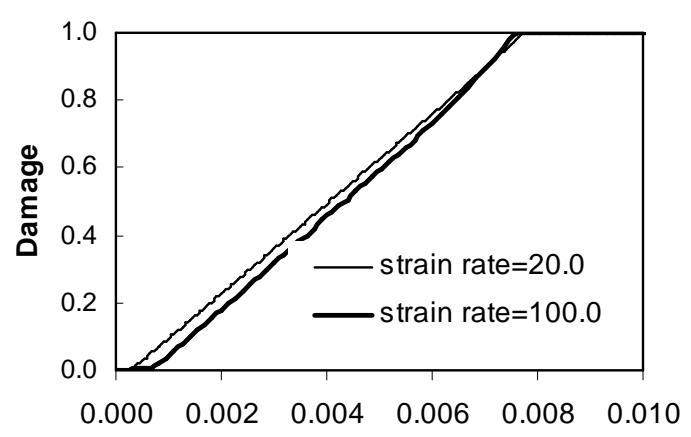

Axial tensile strain

(a) damage vs tensile strain

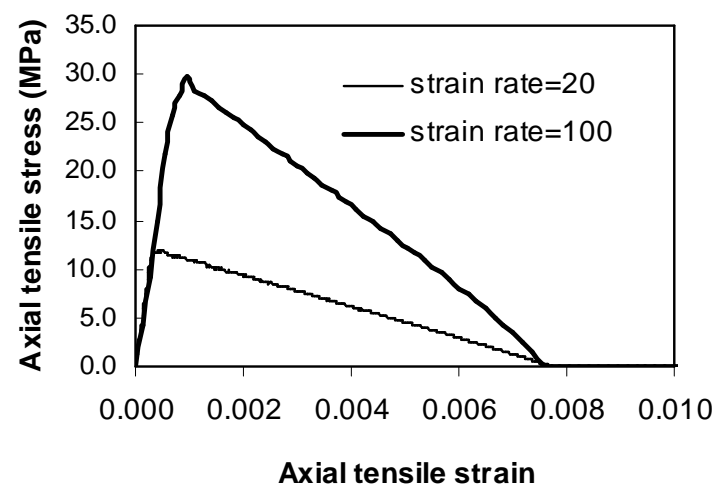

(b) tensile stress vs tensile strain

Fig. 9. concrete uniaxial tension responses resulted from the linear crack softening model.

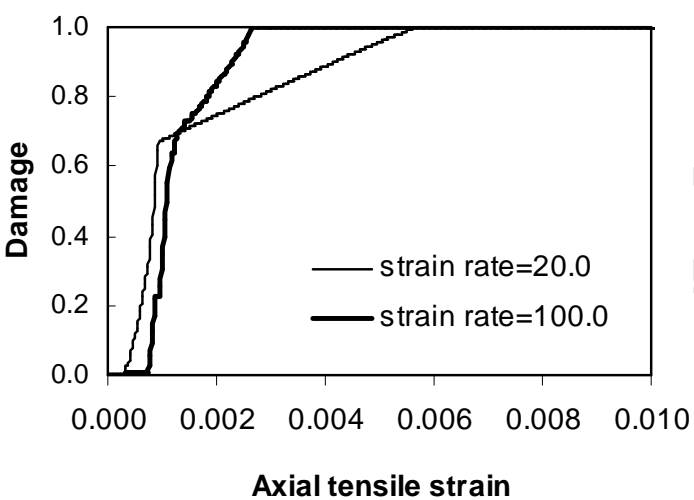

(a) damage vs tensile strain

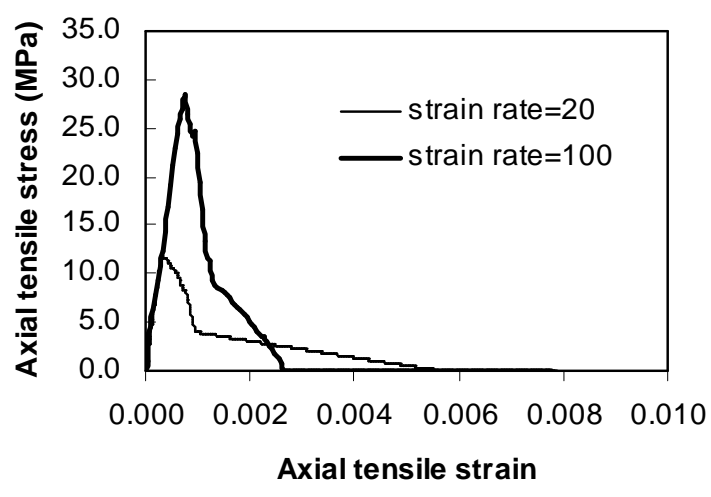

(b) tensile stress vs tensile strain

Fig. 10. Concrete uniaxial tension responses resulted from the bi-linear crack softening model. 


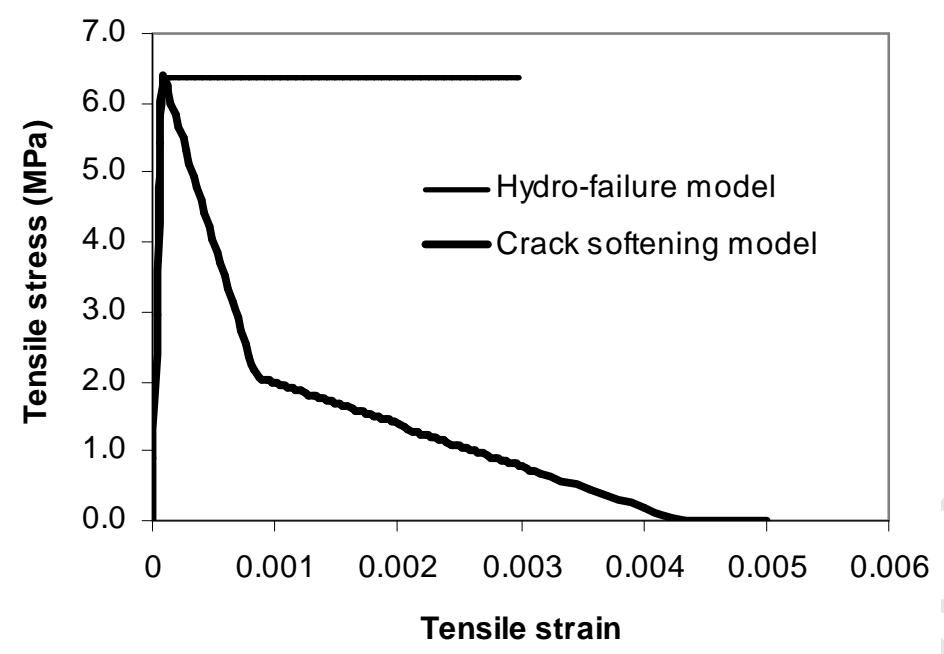

Fig. 11. Comparison of triaxial tension responses resulted from the crack softening and the hydro-failure models.

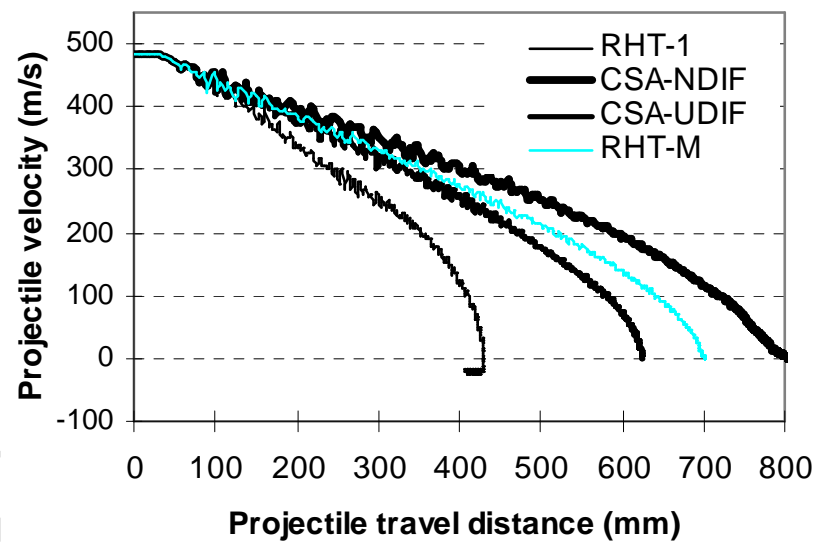

Fig. 12. Comparison of projectile velocity vs. penetration distance curves. 


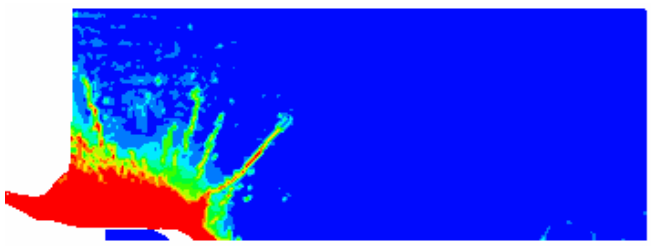

(a) RHT-1

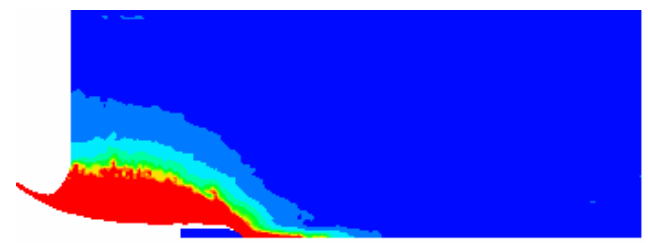

(c) CSA-UDIF

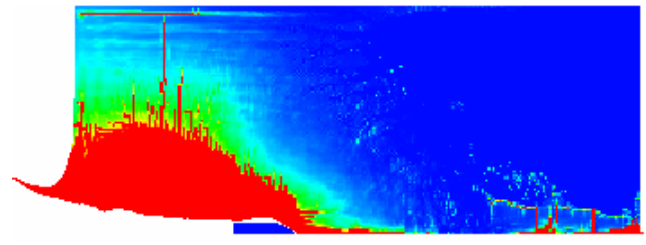

(b) CSA-NDIF

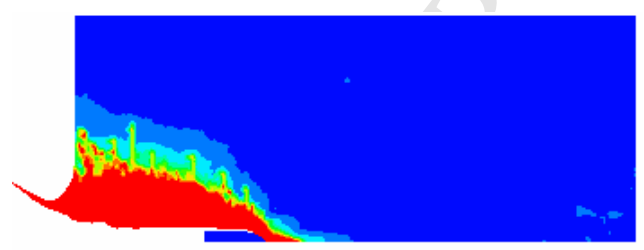

(d) RHT-M

Fig. 13. Comparison of final damage patterns of the concrete target. 


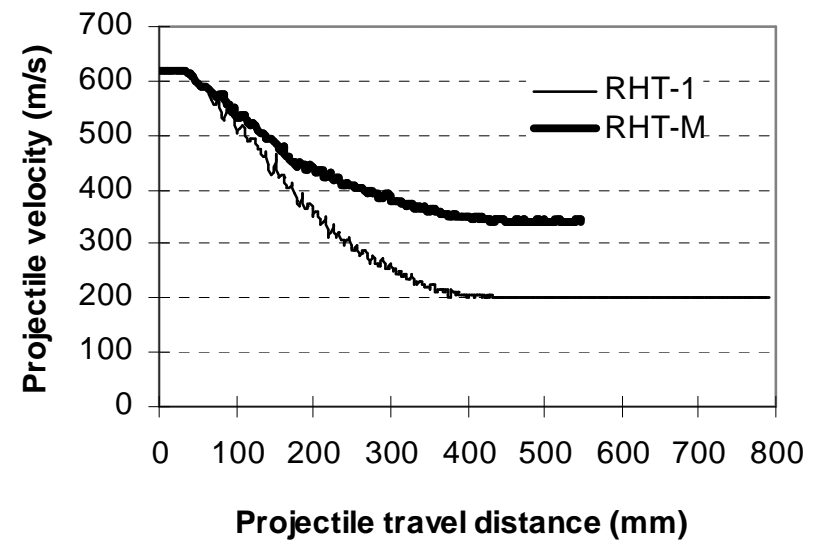

Fig. 14. Projectile velocity vs. penetration distance from simulations of the perforation tests.

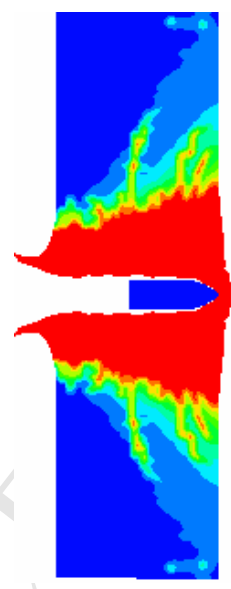

(a) RHT-1

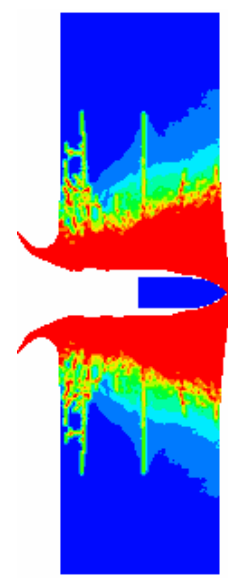

(b) RHT-M

Fig. 15. Simulated damage patterns for the $400 \mathrm{~mm}$ thick perforation tests. 


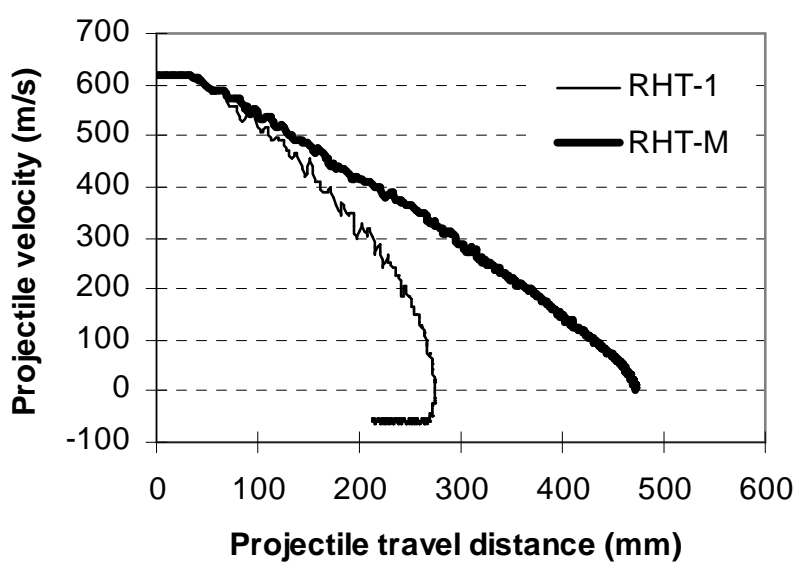

Fig. 16. Projectile velocity vs. penetration depth from simulations of the penetration tests.

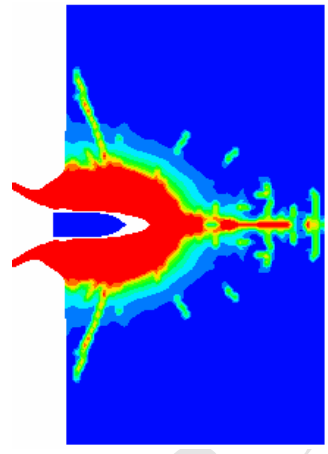

(a) RHT-1

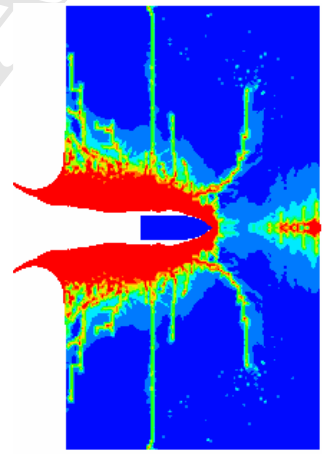

(b) RHT-M

Fig. 17. Simulated damage of the $800 \mathrm{~mm}$-thick concrete target. 